\title{
O Sonderweg do Rio Grande do Sul
}

\author{
The Sonderweg of Rio Grande do Sul
}

René E. Gertz*

Resumo: Dentre as supostas ou efetivas peculiaridades do estado do Rio Grande do Sul, no contexto brasileiro, está a de que, no período republicano, a função dos líderes políticos locais, os "coronéis", seria diferente do restante do país. A discussão historiográfica a respeito vem desde a década de 1960. Este texto sugere que essa discussão deveria ser retomada, pelas profundas implicações das respectivas interpretações, não só para o próprio estado, mas para todo o Brasil.

Palavras-chave: Rio Grande do Sul, "coronel-burocrata”, centralismo político

Abstract: Between the supposed or effective peculiarities of the State Rio Grande do Sul in Brazilian context is the one which tells that, by the republican period, the local political leader's function, the "colonels", was different from the rest of the country. The historiographical discussion about this issue comes from the 60's decade. This text suggests that this discussion should be resumed due, to the deep implications of the respective interpretations, not just for the State itself, but for Brazil as well.

Keywords: Rio Grande do Sul, “coronel-burocrata”, political centralism

O esclarecimento sobre o título de minha intervenção nesta mesaredonda se dará mais para o final. ${ }^{1}$ A título de advertência preliminar, devo destacar apenas as enormes limitações da minha pequena fala. Sempre me dediquei à história política e, portanto, não poderia aventurar-me

* Professor nos Departamentos de História da Pontifícia Universidade Católica do Rio Grande do Sul e da Universidade Federal do Rio Grande do Sul. Porto Alegre, Brasil. E-mail: <gertz@cpovo.net>.

1 Este texto foi, originalmente, apresentado na mesa-redonda "Especificidades do Sul", no X Encontro Estadual de História da ANPUH-RS, realizado na Universidade Federal de Santa Maria, Rio Grande do Sul, de 26 a 30 de julho de 2010. Isso explica o estilo coloquial de algumas passagens, mas como o texto pretende ser, também, um "manifesto", que conclama à retomada de uma discussão, resolveu-se manter o formato original. 
num outro campo, como alguns componentes desta mesa. E nessa perspectiva da história política, não há dúvida de que uma das supostas peculiaridades do Rio Grande do Sul mais popularizadas na tradição historiográfica das últimas décadas está subsumida na expressão "coronel burocrata", a qual se refere a uma realidade que teria conferido ao estado mais sulino do Brasil uma característica bem específica, peculiar, numa comparação com o restante do país, sobretudo quando se atenta para a tradição que se instaurou após a proclamação da República. E é por aí que vou começar a me movimentar, ainda que, mais adiante, esse tema se desdobrará em outras direções. Devo antecipar, também, com toda ênfase possível, que não chegarei a nenhuma grande conclusão inédita, talvez até transpareça uma certa ambivalência em relação ao tema. Por isso, a única intenção é a de delinear alguns aspectos da discussão, recorrendo para isso a frequentes e, às vezes, longas citações, com o objetivo de destacar pontos que parecem centrais, e que, na minha opinião, merecem ser retomados, mesmo que a muitos dos presentes possa parecer que esse tema está totalmente ultrapassado, encerrado.

Penso, pelo contrário, que a grande divergência de opiniões que ficou em aberto após os debates até agora realizados justifica a retomada do assunto, ainda que alguns estarão chacoalhando a cabeça em sinal de desaprovação. Farei uma apreciação muito pessoal, inclusive sem nenhuma pretensão de incluir eventuais resenhas já feitas. O caráter arbitrário na escolha dos autores, e a "leitura" que eu fiz de seus textos visa, justamente, a ser polêmico, pois a própria definição desta mesaredonda me pareceu ter como um de seus objetivos gerar alguma polêmica. Ao final, mediante o recurso à historiografia de um outro país, tentarei mostrar que essa discussão não é bizantina e restrita ao Rio Grande do Sul, que ela também foi travada em outros lugares, incluindo países assim chamados "centrais". Enfim, vou propor que a inconclusão do debate travado no passado justifica sua retomada.

Inicio com uma brevíssima descrição do tema, porque talvez alguns ouvintes mais jovens não estejam totalmente familiarizados com a discussão.

Se minha memória e minhas leituras não me traem por completo, a expressão "coronel burocrata" foi cunhada, originalmente, por Sérgio da Costa Franco, em um artigo intitulado "O sentido histórico da revolução de 1893", de 1962, e retomada em um livro de 1967 chamado Júlio de Castilhos e sua época (Costa Franco, 1962; e Costa Franco, 1967, respectivamente). Mais tarde, ela foi assumida e popularizada por Joseph Love, num livro que consta em qualquer bibliografia que um 
aluno de um curso de História recebe na disciplina de História do Rio Grande do Sul, e leva o título de O regionalismo gaúcho (Love, 1975). O terceiro autor muitas vezes arrolado para exemplificar essa mesma linha de interpretação é Raymundo Faoro, em Os donos do poder (Faoro, 1975).

Mas, em relação a este último, talvez a professora Helga Piccolo não estivesse totalmente errada quando escreveu:

Não é porque Faoro fosse sul-rio-grandense que ele deveria puxar a brasa para o seu estado natal. Mas como pretendia escrever uma obra sobre o Rio Grande do Sul, poder-se-ia esperar que a história do Rio Grande do Sul tivesse um espaço significativo em Os Donos do Poder. Quem assim pensou, como nós, ficou frustrado.

[...].

É nos capítulos XIV e XV, respectivamente, sobre os fundamentos políticos da República Velha e sobre a Revolução de 30, que o Rio Grande do Sul mais aparece, embora palidamente. Nesse sentido, vale-se muito de Joseph Love, transcrevendo trechos do livro já clássico... (...). É de assinalar que a obra de Love é, na bibliografia consultada por Faoro, o livro mais recente de que se valeu. Como já foi dito, o factual é privilegiado por Faoro, sem aportes inovadores (Piccolo, 2004, p. 9-10).

O conceito de "coronel burocrata" recebeu sua primeira contestação mais elaborada por parte de Loiva Otero Félix, em uma tese de doutorado publicada sob o título Coronelismo, borgismo e cooptação política (Félix, 1987). Discípulos da professora Loiva Félix continuaram essa crítica, sob novas perspectivas, como o fez, por exemplo, Gunter Axt, em sua tese de doutorado intitulada Gênese do estado moderno no Rio Grande do Sul (1889-1929) (Axt, 2011). A primeira edição do livro da professora é de 1987. Cinco anos depois, ela publicou um artigo na revista Estudos Leopoldenses, da UNISINOS, chamado "As relações coronelistas no estado borgista: discussão historiográfica". E é desse artigo que vou fazer uma citação mais ou menos longa, para depois tecer alguns comentários.

O poder local no Rio Grande do Sul continuou forte, ao longo das duas décadas do século $[\mathrm{XX}]$, não se chocando nem sendo anulado pelo Estado borgista, mas perfeitamente ajustado a ele, numa política de controle e complementariedade, estabelecendo-se o compromisso coronelista, através da intermediação dos subchefes de polícia. Em geral, o coronel gaúcho não tinha força suficiente 
para o enfrentamento e [a] negociação direta com o Estado, pois no Rio Grande do Sul o poder estadual não é fraco diante do poder local, como foi a regra na grande maioria dos estados brasileiros. No Rio Grande do Sul, o poder local era forte, mas também o eram o Estado/Partido. Não sendo possível, nem desejado, o enfrentamento, a solução ideada por Castilhos e continuada por Borges, foi a de um comportamento político intermediário, integrando os coronéis à estrutura partidária, colocando-os nas comissões diretoras dos diretórios municipais do PRR e investindo-os em funções políticas intendenciais, nos conselhos intendenciais (ou municipais) e nas funções políticas do município e do distrito. Na verdade, o grande poder estava no partido, representado pelo Poder Executivo. O poder das comissões executivas era figurativo (conseguir emprego, abrir estradas etc...). Com isso, delineou-se um tipo de coronelismo conhecido como de modelo borgista, onde se uniam a cooptação e a coerção. Aqui [sim] parece-nos residir uma diferença na relação do Estado com o poder local relativamente à maioria dos demais estados, onde a força do coronel era maior diante de poderes estaduais (Félix, 1992, p. 83).

Para comentar alguns aspectos das afirmações contidas nessa longa citação, torna-se necessário apresentar, ainda que de forma absolutamente resumida, aquilo que Sérgio da Costa Franco, Joseph Love e Raymundo Faoro - os três citados pela professora Loiva como comprometidos com o conceito do qual ela discorda - escreveram sobre o "coronel burocrata". Costa Franco o definiu como "chefe municipal, às vezes sem fortuna e sem raízes locais, porém armado de extraordinários poderes de coação, e inteiramente submisso à executiva do partido e ao presidente [do estado]" (Costa Franco, 1962, p. 215). ${ }^{2}$ Love, por sua vez, deu maior ênfase à diferenciação em relação ao restante do país, quando escreveu que "em outros estados, o coronel obtinha usualmente sua posição no partido oficial em função de seu poder econômico e prestígio social dentro de certa área. Apesar de estes fatores terem um significado no Rio Grande [do Sul], existia uma qualificação indispensável para alguém exercer o poder local: a disposição de acatar decisões partidas de cima" (Love, 1975, p. 84).

Quanto a Faoro, além da crítica de Helga Piccolo de que ele, na verdade, não traria nada de novo além daquilo que, antes dele, dissera Love, a coerência de seu posicionamento ao longo de todo o livro $O s$ donos do poder sugere que as peculiaridades ou diferenças a que ele

2 A frase foi repetida quase ipsis litteris em Costa Franco, 1967, p. 203. 
se refere devam ser classificadas muito mais de "nominalistas" que de "essencialistas", entre os coronéis do Brasil, em geral, e os do Rio Grande do Sul, em particular.

Que ninguém vá buscar na tradição filosófica universal uma definição dos adjetivos "nominalista" e "essencialista" - o que quero dizer é que para Faoro essa diferença, provavelmente, não era fundamental para a tese central do seu livro. É possível, por isso, que aquilo que a própria professora Loiva aponta em sua contribuição para o tema esteja no fato de ele ter valorizado um coronel que é formalmente burocrata, com destaque especial para o oficial da Brigada Militar. Assim, numa pergunta retórica, Faoro escreveu: "Por que não simplifica[r] as coisas, com a adoção do modelo Borges de Medeiros, transformando o coronel em burocrata, cujo padrão seria o coronel da Brigada Militar?" (Faoro, 1975, p. 638). Essa frase talvez nos autorizasse a dizer que, na opinião do autor, o coronel sul-rio-grandense constituía o modelo - ou o "tipoideal" - mais "perfeito" do coronel brasileiro. ${ }^{3}$

Apresentadas, dessa forma extremamente fragmentada e resumida, as posições de ambos os lados, vamos a algumas poucas considerações. Como mostra a citação da professora Loiva, ela própria admite uma diferença daquilo que chama "modelo borgista" de coronel, na comparação com o modelo supostamente dominante nos demais estados brasileiros. Mas eu penso que da mesma forma que Faoro admite essa diferença, sem que ela seja - para ele - qualitativamente decisiva, e, por isso, apenas "nominalista", assim também a professora Loiva admite que a diferença existe, mas não teria peso fundamental. Vejo a questão da seguinte forma: em Faoro, o modelo patrimonialista caracterizaria o Brasil como um todo, e esse modelo poderia registrar no Rio Grande do Sul sua versão mais elaborada, sem que fosse fundamentalmente diferente. Inversamente, para a professora Loiva o modelo daquilo que ela chama de "cooptação" (expressão que aqui é apresentada sem comentário, mas à qual se voltará mais adiante) caracterizaria a situação brasileira como um todo, e se apresentaria de forma apenas um pouco diferente no Rio Grande do Sul.

Se essa interpretação é correta, as críticas a Sérgio da Costa Franco e a Joseph Love teriam outra base, se localizariam em outro patamar. Trata-se da discussão sobre as relações fundamentais de Estado versus Sociedade ou, em outros termos, da discussão sobre o primado

3 Tenho plena consciência de que essa possa ser uma simplificação, mas creio que uma "leitura" "ideal-típica" a justifica. 
da política, por um lado, ou o primado de economia e sociedade, por outro lado. E nessa perspectiva, é possível fazer deduções em várias direções. Até se poderia chegar a ver nesses dois autores um endosso - ainda que subentendido e, certamente, não intentado - daquilo que costuma ser chamado de "historiografia tradicional" situacionista sobre o tema, com sua ênfase em grandes personalidades. Pois se aqui no Rio Grande do Sul vigora o primado da política, essas personalidades poderiam ser vistas como agindo em favor do interesse comum, como grandes líderes políticos, que se empenhariam pelo bem da "nação" gaúcha. Dessa forma, a assim chamada "historiografia tradicional"4 poderia estar sugerindo que aqui o poder dos grupos socioeconômicos estava submetido a algum controle, que aqui bons políticos faziam uma administração a favor do bem comum - é evidente que uma "historiografia tradicional" oposicionista dizia o contrário.

Mas, inversamente, pode-se desqualificar afirmações desse tipo as quais, sem dúvida, tentam refletir uma imagem positiva da política gaúcha - como "ideológicas", por tentarem encobrir a dominação de grupos de interesse socioeconômicos, de frações de classe ou de classes. Tanto nos textos da professora Loiva quanto na tese de Gunter Axt, defende-se justamente o posicionamento de que também no Rio Grande do Sul a dominação socioeconômica foi muito parecida com aquela do restante do Brasil (e do mundo), e que a hegemonia política correspondia, de forma simétrica, a essa dominação. Em vez de uma frase da professora Loiva, recorro aqui a uma frase de Gunter Axt, ao definir o sentido de sua tese de doutorado: "A reflexão conduzida nesse trabalho foi inspirada, de uma parte, na discussão historiográfica brasileira sobre o sistema coronelista, e, de outra, nos conceitos do atual debate marxista acerca das funções e características da instituição estatal em conexão direta com os interesses sociais" (Axt, 2011, p. 12 - os grifos foram acrescentados ao original).

Espero não estar errando na "leitura" dessa frase, mas entendo que ela queira dizer que o coronelismo no Rio Grande do Sul não possui nada de essencialmente diferente daquele do restante do país, e que todo e qualquer coronelismo reflete uma correspondência entre dominação socioeconômica e poder político (abstraindo, é claro, de eventuais detalhes sobre "autonomia relativa" do Estado, e coisas do gênero). Poderia dizer-se, também, que Gunter Axt queria mostrar que

4 Tanto Loiva Otero Félix (1992, p. 69) quanto Gunter Axt (2011, p. 17) referem-se, de forma expressa, a essa suposta terceira tradição historiográfica. 
existe um caminho "normal" de concretização da "lógica" dos interesses socioeconômicos dominantes, em qualquer parte do mundo, e que no Brasil - incluindo o Rio Grande do Sul - não foi diferente. Quem, entre os historiadores acadêmicos, pleiteia uma peculiaridade para o estado gaúcho poderia correr o risco de parecer tão "ideológico" quanto os historiadores chamados "tradicionais", com suas louvações aos "grandes homens", que são pressupostos - nesse tipo de historiografia - como agindo acima e independentes da citada "lógica". ${ }^{5}$

Antes de prosseguir, convém fazer um parêntese para observar que, na tradição intelectual brasileira, com muita frequência, não só o Rio Grande do Sul é apresentado como diferente daquilo que se supõe como "normal". Há uma tradição de pensamento muito forte - ao menos no período republicano - que apresenta o Brasil todo como diferente, e, em geral, negativamente diferente, de algo que seria "normal". ${ }^{6}$ Sérgio Buarque de Holanda (1936), com sua classificação de "homem cordial", vai nessa direção, pois o autor não queria elogiar-nos com essa expressão. O citado Raymundo Faoro (1975), com seu diagnóstico sobre os efeitos nefastos do patrimonialismo, é outro exemplo na mesma direção.

Entre autores contemporâneos de Buarque de Holanda e de Faoro, temos um diagnóstico correspondente, ainda que em sentido inverso. Se nos termos da discussão atual o diagnóstico de Holanda e Faoro passava pelo lamento do não-funcionamento daquilo que se poderia chamar de "modelo de mercado" - que seria o "normal" -, já nos anos 1920 aqueles que - em artigo clássico de Bolívar Lamounier (1977) - foram rotulados de "ideólogos do Estado" pensavam que no Brasil se tentara implantar, equivocadamente, porque de forma artificial, uma "normalidade" que aqui não tinha chance de prosperar, motivo pelo qual se teria de implantar algo diferente, para lidar com as deficiências e as mazelas produzidas pela ordem liberal, pelo "mercado", que foi artificialmente intentada. Interpretando o posicionamento desses pensadores, poderia dizer-se que, no Brasil todo, uma ordem política baseada no primado de economia e sociedade não tinha possibilidade de vingar, e que a confusão derivada dessa opção só seria sanada com a implantação de algo diferente, o estabelecimento da primazia do político. Nessa perspectiva, no Brasil

5 Quanto à discussão em torno das relações do poder local com o poder regional ou mesmo nacional, no Brasil, pode-se recorrer a Carvalho, 1998.

6 Existem também avaliações que apresentam um Brasil positivamente diferente, linha de interpretação que pode passar pelo conde Affonso Celso (1900), por Gilberto Freyre (1933), e desembocar, na atualidade, em autores como Jessé Souza (2000). Cf. Sell, 2007. 
se teria cometido um grande erro ao tentar ser "normal". E, por isso, a construção de algo diferente, a implantação de uma realidade em que houvesse a supremacia da política, constituiria um imperativo ético, político.

Chama a atenção que os formuladores desta última concepção, com sua respectiva proposta, são, muitas vezes, classificados como "protofascistas", como precursores e ideólogos da ditadura estadonovista. Mas, de repente, a gente se surpreende que num livro de um dos mais destacados ideólogos do esquerdista ISEB, lá na década de 1950, se encontra um elogio escancarado a essa gente. Trata-se de Alberto Guerreiro Ramos, em seu livro A crise do poder no Brasil. Ele dedicou três capítulos a correntes de pensamento do período da revolução de 1930: a "ideologia da ordem", representada, sobretudo, pelo pensamento arquiconservador católico; as elocubrações da "jeunesse dorée", que seriam produto de pensadores com barriga cheia; e, finalmente, aqueles que seriam classificados, de forma injustamente pejorativa - segundo o autor -, como "inconsciente sociológico", entre os quais arrolou os citados "protofascistas". Nesse contexto, Guerreiro Ramos escreveu que, "ao reler os trabalhos de Azevedo Amaral, ninguém pode furtarse à verificação de que neles está presente o estudioso mais lúcido e competente da década de 1930" (Ramos, 1961, p. 178-179). Não tenho dúvida de que devemos interpretar essa afirmação como um claro endosso à "ideologia de Estado", e, nesse sentido, a tradição gaúcha do primado da política pode ser vista como indiretamente elogiada. E veremos que não estou falando de uma hipótese abstrata. Vou citar ao menos um autor que se alinha, claramente, a essa orientação. ${ }^{7}$

Feito esse excurso sobre alguns autores que destacam a peculiaridade do Brasil como um todo, devo fazer uma referência a mais dois autores que se dedicam às supostas ou efetivas especificidades do Rio Grande do Sul, e sua inserção no Brasil. O primeiro deles é Simon Schwartzman, um dos mais destacados discípulos de Raymundo Faoro. Mas se aqui foi dito que o mestre, aparentemente, não deu importância fundamental a uma possível diferença do nosso estado frente à situação do país como um todo, o discípulo, sem dúvida, viu a situação numa perspectiva bastante diferente. Em 1975, Schwartzman publicou um livro intitulado São Paulo e o Estado Nacional. Ainda que uma versão revisada do mesmo tenha sido publicada em 1982, como Bases do autoritarismo brasileiro, não

\footnotetext{
7 A bibliografia a respeito da contraposição entre "idealismo constitucional" e "idealismo orgânico", subjacente a essa discussão, é extensa, motivo pelo qual remeto a apenas um autor: Brandão (2007, em especial, p. 21-67).
} 
há dúvida de que o título da primeira edição é extremamente importante para uma compreensão adequada daquilo que aqui nos interessa. $\mathrm{O}$ autor propõe uma regionalização do Brasil, destacando quatro regiões básicas: a Capital (historicamente, o Rio de Janeiro), as regiões "tradicionais" (que seriam aquelas que tiveram esplendor econômico, no passado, mas o perderam - concretamente: Minas Gerais e Nordeste), São Paulo (com seu desenvolvimento relativamente independente em relação ao poder político central), e Rio Grande do Sul. Sobre este último estado, o autor afirma que sempre desempenhou, no contexto nacional, um papel político proporcionalmente superior a sua importância econômica; de forma que, apesar da marginalidade geográfica, no mínimo desde o final do século XIX, faz parte do centro da política nacional; por sua posição de fronteira militar, desenvolveu um peculiar amálgama entre uma tradição militar local e a "cultura boiadeira"; e assim, "o papel político do Rio Grande, a nível nacional, tem, historicamente, mais a ver com sua tradição militar, caudilhesca, revolucionária e oligárquica do que com os aspectos modernos e europeizados de sua economia e sociedade"; internamente, a política não é tradicional e baseada em fidelidades construídas em algum momento do passado, quando a economia era mais dinâmica (Schwartzman, 1975, p. 52-54; a citação está na p. 54).

Importante nessa visão de Schwartzman é que nem tudo no Brasil está perdido. Há uma região que tinha, e - apesar do pessimismo confesso do autor - continua tendo tudo para dar certo: São Paulo. Mas esse estado foi manietado pelo tradicionalismo do restante do Brasil, e, sobretudo, pelo predomínio político exercido e difundido pelo Rio Grande do Sul.

"Neste livro, será proposta uma relação íntima entre 'patrimonialismo', uma característica estrutural, e 'cooptação política', própria do nível político" (Schwartzman, 1975, p. 21); “cooptação política tende a predominar em contextos em que estruturas governamentais fortes e bem estabelecidas antecedem historicamente os esforços de mobilização política de grupos sociais" (Schwartzman, 1975, p. 22). À cooptação contrapõe-se a "representação",

modelo [que] supõe que o surgimento de uma economia capitalista mais ativa em um país tende a gerar grupos de interesse ativos nos dois lados da divisão social de classes. O tipo de política que assim emerge implica, geralmente, em mais preocupação com políticas governamentais que com empregos; quando os políticos 
aumentam seu poder e prestígio, aumenta também a necessidade de as lideranças corresponderem às expectativas e demandas das bases que lhes outorgam poder. Eles podem tornar-se burocratas de seus partidos, mas dificilmente burocratas governamentais.

[...].

É possível mostrar que, se formas embrionárias de representação política existiram no Brasil, elas tenderam a se concentrar na área de São Paulo. Elas nunca chegaram a ser suficientemente fortes para moldar o quadro político nacional, mas foram suficientemente significativas para manter o estado de São Paulo como uma entidade politicamente diferenciada dentro do país (Schwartzman, 1975, p. 23-24).

É claro que, na opinião de Schwartzman, no Rio Grande do Sul teria vigorado o modelo de cooptação. ${ }^{8}$

Quem conhece a obra de Schwartzman - e o próprio título indica muita coisa - sabe que aquilo que ele defende é que São Paulo foi a região que apresentava elementos embrionários de um desenvolvimento "normal" para o Brasil, para a implementação de uma ordem liberal, um estado moderno, não-patrimonialista. E, nesse sentido, São Paulo apresenta uma peculiaridade única positiva frente ao restante do país. Se essa tendência não tivesse sido frustrada, abafada, o Brasil poderia ser um país desenvolvido. Parafraseando uma conhecida propaganda de vodka, poderia dizer-se que aquilo que São Paulo poderia ter sido, o Brasil todo poderia ser hoje. Infelizmente, o Rio Grande do Sul teve um papel muito importante para impedir que esse "efeito Orloff" se concretizasse neste país. Desgraçadamente, a política de "cooptação" gaúcha teria sido vitoriosa sobre a política de "representação" paulista - e essa seria a tragédia do Brasil, segundo Schwartzman. ${ }^{9}$

Mas, numa prática que possui alguma tradição na história intelectual do planeta, muitas vezes, intelectuais aproveitam seu inspirador para

8 Ainda que não se queira aprofundar essa questão, parece que a professora Loiva não tem a mesma compreensão da palavra "cooptação". Mesmo que a diferença com a concepção de Schwartzman não fique totalmente evidente na definição formal do conceito, na introdução do livro (Félix, 1987, p. 16), as diferenças ficam mais claras no citado artigo. Numa crítica a um trabalho de Alírio Eberhardt, a autora diz o seguinte: "O próprio autor contradiz-se quando, no trecho anteriormente citado, nega a existência de cooptação no RS e, mais adiante, reconhece o poder dos coronéis e sua relação com o governo" (Félix, 1992, p. 74). Essa frase sugere que a autora quer dizer que a "cooptação" constitui o padrão "normal" de coronelismo em todo o país - enquanto em Schwartzman "cooptação" é aquilo que não é típico da "normalidade" paulista, mas sim da "peculiaridade" do Rio Grande do Sul.

9 Sem entrar em detalhes, cabe referir também o debate travado entre Schwartzman e Richard Morse, no final da década de 1980, resumido por Oliveira, 2000. 
virá-lo de cabeça para baixo, a fim de propor ou pleitear o inverso daquilo que ele disse ou defendeu. Nessa linha, Luiz Roberto Pecoits Targa, em artigo intitulado "Negações da identidade do Rio Grande do Sul", abriu uma nota de rodapé com um grande elogio a Schwartzman, louvando-o por ter sido um dos poucos a destacar e a assumir as diferenças do Rio Grande do Sul em relação ao restante do Brasil. "O resultado de toda essa valentia intelectual [daqueles que tentam negar as peculiaridades do Rio Grande do Sul] é o de borrar a fisionomia da história do Sul, o de esmaecer seus traços característicos. No fundo, o que a maioria precisa negar é a autonomia e a individuação da formação histórica meridional". E a essa observação Targa acrescenta a seguinte nota: "Existe uma notória exceção: Simon Schwartzman. Ele distingue quatro regiões com culturas políticas distintas no Brasil: (a) a constituída pelo centro político nacional (Rio de Janeiro, depois Brasília); (b) a constituída por Minas Gerais e o 'resto do País'; (c) a de São Paulo; e (d) a do Rio Grande do Sul" (Targa, 2003b, p. 301). ${ }^{10}$

De fato, nesse artigo, e também noutro sobre a revolução federalista de 1893-95, publicado antes, no mesmo ano, Targa coloca Schwartzman de cabeça para baixo. Se este enxerga em São Paulo um potencial para trilhar o caminho "natural" da modernização do Brasil, com seus ensaios de implantação de uma política de "representação", ensaios que, infelizmente, teriam sido frustrados pela política de "cooptação" praticada pelo Rio Grande do Sul, e exportada para todo o país, sobretudo a partir de 1930 e a subseqüente subjugação de São Paulo neste ano e, depois, em 1932, ele, Targa, transforma o Rio Grande do Sul no centro irradiador da ação salvífica do país.

Como não disponho de tempo para uma análise minuciosa do texto, vou reproduzir as frases inicial e final do artigo de Targa:

É evidente, para qualquer pessoa de bom senso, seja ela um sul-riograndense, seja um outro brasileiro, que o mundo do Sul, mesmo hoje em dia, continua sendo muito distinto dos demais mundos brasileiros, e muito mais do que eles o são entre si. No entanto, a maior parte dos intelectuais gaúchos formados nas escolas do "centro" - assim como, é claro, a própria intelectualidade das universidades do "centro" - decidiu que não é assim. Todos resolveram que o Rio Grande do Sul deveria ser igual ao resto do País. Para esses intelectuais, obviamente, o seu exercício lhes

${ }^{10} \mathrm{O}$ artigo de Targa deriva de sua tese de doutorado (Targa, 2002), a qual não foi utilizada aqui. Uma rápida resenha da mesma pode ser conferida em Heinz, 2006, p. 144-145. 
parece ser o de ir além das aparências. No entanto, não vão. O que fazem é repetir o modelo interpretativo ensinado no "centro".

$[\ldots]$.

Possuímos enormes dúvidas quanto à possibilidade de pensarmos que uma economia e uma sociedade periféricas sejam capazes de gerar experiências políticas de vanguarda no contexto nacional, fato que quer dizer, para nós, que a sociedade meridional nunca foi uma sociedade periférica. No bem dizer de Vitor Ramil, ela é "o centro de uma outra história” (Targa, 2003b, p. 300 e 319-320).

Com isso, o autor quer dizer que se algo de bom aconteceu ao Brasil foi o fato de o Rio Grande do Sul ter sido diferente. Se para Simon Schwartzman o "efeito Orloff" (isto é, a possibilidade de, amanhã, sermos todos iguais a São Paulo - e mais: iguais ao "primeiro mundo"), infelizmente, não aconteceu, para Targa, felizmente, aconteceu algo de ótimo, em sentido inverso, pois, mesmo que o Brasil ainda não se tenha convencido, talvez um dia venha a convencer-se de que se hoje o país apresenta algo de bom - sua industrialização, sua modernização, sua legislação social - ele o deve ao fato de ter-se transformado naquilo que o Rio Grande decidiu ser ontem, graças à clarividência de Júlio de Castilhos.

Esse impasse historiográfico - mas também ético, normativo, político - em que nos encontramos não é exclusivamente gaúcho e brasileiro. Um dos mais importantes debates na mesma direção realizouse na Alemanha, sob a rubrica do Sonderweg, a "via peculiar" - motivo do título deste texto. Na tradição de língua portuguesa certamente é mais conhecida a expressão "via prussiana" para designar o modelo alemão que, supostamente, lá se desenvolveu, no mínimo, desde meados do século XIX, mas, sobretudo, depois da unificação alemã, em 1871. Mais ou menos como no caso do Rio Grande do Sul, a ideia de um desenvolvimento sui generis foi encarada, durante muito tempo, sob uma luz positiva - intelectuais e políticos alemães enxergavam a "peculiaridade" alemã como elemento vantajosamente distintivo frente ao restante da Europa, e também frente à continuidade do suposto ou efetivo absolutismo oriental, russo.

Segundo o historiador Winfried Schulze, "enquanto [o conceito de Sonderweg] expressava, ao final do século XIX, a certeza que a Alemanha tinha de si mesma de que era superior aos sistemas políticoculturais da Europa ocidental, constituindo, portanto, a partir da perspectiva alemã, um conceito positivo, ele se transformou, sobretudo depois da Segunda Guerra Mundial, em um modelo de interpretação negativo, utilizado para explicar a 'catástrofe alemã'” (Schulze, 2002, 
p. 229). ${ }^{11}$ Hans-Ulrich Wehler foi um dos principais historiadores a se preocupar com a perspectiva do Sonderweg, e, segundo ele, as pesquisas a respeito "destacaram os efeitos do fracasso da revolução de 1848 e do regime autoritário de Bismarck, que durou três décadas, mostraram as fraquezas dos partidos e do sistema parlamentar, a força continuada das velhas elites agrárias, da burocracia e do exército, a influência de valores e normas tradicionais, mesmo em um período que se caracterizou pela rápida modernização econômica da Alemanha" (Wehler, 1998, p. 79).

Wehler, ao detalhar aspectos empíricos do Sonderweg - que ele trata como realmente existente, e não apenas como "ideologia" - refere os seguintes elementos: tensão entre tradição e modernidade; domínio prussiano; posição antiparlamentar e antidemocrática; absolutismo esclarecido, que executou algumas reformas até antes da Revolução Francesa, levando, porém, a uma prática de submissão e de fidelidade incondicional à autoridade constituída; destaque especial para o ser alemão e sua especificidade em relação aos demais povos da Europa; tendência de enfatizar a cultura alemã, em contraposição à civilização universal (a primeira seria histórica, emocional, hierárquica; a segunda seria abstrata, racional, democrática de massas); o modelo teria levado a uma modernização socioeconômica rápida, mas a modernização política teria sido prejudicada, com a permanência de elites prémodernas (Junker), e uma burguesia sem acesso direto ao poder, assim que a frustração resultante das restrições ao poder da burguesia teria derivado para o nacionalismo, o antissemitismo, o militarismo, o colonialismo. $^{12}$

Ainda que essa visão sobre o Sonderweg não seja unânime na historiografia alemã, ela teve uma grande aceitação depois da Segunda Guerra Mundial, e esteve no centro de uma das mais acirradas "querelas" de que os historiadores alemães participam, de tempos em tempos, desde, no mínimo, o final do século XIX. Trata-se da assim chamada "querela de historiadores", o Historikerstreit, que, cronologicamente, se concentrou nos anos de 1986 a 1988. Entre os muitos aspectos envolvidos nessa querela estava a pergunta se o nazismo e o consequente Holocausto constituíram um simples "acidente" histórico, ou se eles foram um resultado óbvio, teleológico, do Sonderweg alemão, do desenvolvimento "peculiar" da Alemanha? ${ }^{13}$

\footnotetext{
${ }^{11}$ Resenhas sobre a discussão historiográfica em torno do Sonderweg podem ser vistam em Kocka, 1982; Peter, 1995, p. 143-152.

12 Cf. também Kocka, 1982.

${ }^{13}$ Sobre o Historikerstreit, cf. Peter, 1995; Borowsky, 2005; Pohlmann, 2007.
} 
Talvez um pouco parecido com nosso debate sobre as peculiaridades do Rio Grande do Sul, a "querela de historiadores" alemães não chegou a um ponto final, e, muito menos, a um consenso. A própria queda do muro, em 1989, pode ter levado a sua suspensão. Mas justamente a reunificação fez com que alguns historiadores alertassem para os perigos que essa nova situação poderia representar em tentativas de percorrer, mais uma vez, uma "via peculiar", um novo Sonderweg para o país reunificado. Nesse sentido, um dos mais destacados historiadores alemães, Jürgen Kocka, escreveu na conhecida revista Die Zeit, em 1990, um artigo com o significativo título "Por favor, não venham com um novo Sonderweg - qualquer parcela de desocidentalização constituiria um preço demasiadamente elevado para a unidade alemã" (Kocka, 2001, p. 68-77).

Claro, no Rio Grande do Sul e no Brasil não ocorreu um Holocausto - ao menos não de 6 milhões de seres humanos. Tivemos os mais de 10 mil mortos da Revolução Federalista, um número não muito preciso de mortos no Estado Novo ${ }^{14}$, mais as centenas de mortos, desaparecidos e torturados do regime militar. E podemos encarar essa trajetória como consequência das maldades iniciadas por Júlio de Castilhos - "o homem que inventou a ditadura no Brasil" (Freitas, 1998) -, continuadas pelo maquiavelismo de Getúlio Vargas durante, no mínimo, 15 anos, e retomadas pelo autoritarismo dos três generais gaúchos que governaram o Brasil durante o regime militar.

Mas pode-se contar essa trajetória também por outro ângulo: ela teria começado com a gloriosa vitória de Júlio de Castilhos na Revolução Federalista, já que, na opinião de Luiz Roberto Targa, por exemplo, "a ditadura [então] instalada pelos positivistas possui[u] a função necessária de afastar a oligarquia tradicional do poder regional" (Targa, 2003a, p. 148 - grifo acrescentado ao original); continuou depois com a clarividência de Getúlio Vargas em relação ao processo de modernização do país, com o desenvolvimentismo, a industrialização e a inclusão da classe operária; e, mesmo que alguns ainda terão pruridos em fazer elogios expressos aos governos de Costa e Silva e, sobretudo, de Médice, com um pouco de coragem, o nome de Geisel já pode ser pronunciado, sem maiores problemas, como continuador desse processo,

\footnotetext{
${ }^{14}$ Um historiador que destaca a continuidade entre a tradição (não necessariamente "negativa") do castilhismo e o Estado Novo é Hentschke (2004). A respeito do "ensaio" intervencionista de Vargas enquanto governador do Rio Grande do Sul (1928-1930), cf. Axt (2006).
} 
pois, afinal, seu programa estatizante talvez não tenha sido dos piores, e ele até "peitou" os Estados Unidos. ${ }^{15}$

Por tudo isso, em vez de dar por encerrada nossa discussão sobre a "via peculiar" do Rio Grande do Sul, talvez não fosse de todo desaconselhável desencadear também entre nós um Historikerstreit, uma "querela de historiadores". ${ }^{16} \mathrm{O}$ tema, com certeza, comporta mais debates, seja na perspectiva normativa, política, seja na perspectiva historiográfica. Não é de todo indiferente qual das duas alternativas se esteja trilhando ou se queira trilhar.

\section{Referências}

AXT, Gunter. The origins of an “enigma”: Getúlio Vargas, Rio Grande do Sul's decaying coronelismo, and the genesis of the interventionist state before the 1930 revolution. In: HENTSCHKE, Jens R. (ed.). Vargas and Brazil: new perspectives. New York: Palgrave Macmillan, 2006. p. 31-53.

AXT, Gunter. Gênese do estado moderno no Rio Grande do Sul 1889-1929. Porto Alegre: Paiol, 2011.

BOROWSKY, Peter. Der Historikerstreit. Wie geht die Deutsche Geschichtswissenschaft mit der nationalsozialistischen Vegangenheit um? In: BOROWSKY, Peter. Schlaglichter historischer Forschung. Studien zur deutschen Geschichte im 19. und 20. Jahrhundert. Hamburgo: Hamburg University Press, 2005. p. 63-87. Disponível em: $<$ http://hup.sub. uni-hamburg.de/opus/volltexte/2008/9/pdf/HamburgUP_Borowsky_Schlaglichter.pdf>. BRANDÃO, Gildo Marçal. Linhagens do pensamento politico brasileiro. São Paulo: Aderaldo \& Rothschild Editora, 2007.

CARVALHO, José Murilo de. Mandonismo, coronelismo, clientelismo: uma discussão conceitual. In: CARVALHO, José Murilo de. Pontos e bordados: escritos de história e política. Belo Horizonte: Editora UFMG, 1998. p. 130-153.

CELSO, Affonso. Porque me ufano do meu país. São Paulo: Laemmert, 1900.

COSTA FRANCO, Sérgio da. O sentido histórico da revolução de 1893. In: Fundamentos da cultura rio-grandense. Porto Alegre: Faculdade de Filosofia da Universidade Federal do Rio Grande do Sul, 1962. p. 193-216.

COSTA FRANCO, Sérgio da. Júlio de Castilhos e sua época. Porto Alegre: Globo, 1967.

FAORO, Raymundo. Os donos do poder. Porto Alegre: Globo, 1975.

FÉLIX, Loiva Otero. Coronelismo, borgismo e cooptação política. Porto Alegre: Mercado Aberto, 1987.

15 O Estado de São Paulo de 29 de abril de 2010 noticiou que o presidente Lula disse que Ernesto Geisel foi “o presidente que comandou o último grande período desenvolvimentista do país".

16 Tivemos um "momento denso" dessa discussão no início do século XXI, pois em três anos surgiram três teses de doutorado a respeito: Herrlein Jr., 2000; Axt, 2011 (original de 2001); e Targa, 2002. Mas, aparentemente, essa discussão não se "popularizou" entre historiadores-políticos. 
FÉLIX, Loiva Otero. As relações coronelistas no estado borgista: discussão historiográfica. Estudos Leopoldenses, São Leopoldo, v. 28, n. 127, 1992.

FREITAS, Décio. O homem que inventou a ditadura no Brasil. Porto Alegre: Sulina, 1998.

FREYRE, Gilberto. Casa grande e senzala. Rio de Janeiro: José Olympio, 1933.

HEINZ, Flávio M. Elites, estado y reforma en Uruguay y Brasil meridional: castilhismo y batlismo em perspectiva comparada. El caso de las elites de Rio Grande do Sul en la transición del siglo XIX al XX. In: REGUERA, Andrea et al. Los rostros de la modernidad: vias de transición al capitalismo: Europa y América Latina - siglos XIX/ XX. Rosario: Prohistoria Ediciones, 2006. p. 137-161.

HENTSCHKE, Jens R. Positivism gaúcho-style: Júlio de Castilho's dictatorship and its impact on state and nation-building in Varga's Brazil. Berlim: Verlag für Wissenschaft und Forschung, 2004.

HERRLEIN Jr., Ronaldo. Rio Grande do Sul, 1889-1930: um outro capitalismo no Brasil Meridional? Tese (Doutorado) - UNICAMP, Campinas, 2000.

HOLANDA, Sérgio Buarque de. Raízes do Brasil. Rio de Janeiro: Livraria José Olympio Editora, 1936.

KOCKA, Jürgen. Der “deutsche Sonderweg” in der Diskussion. German Studies Review, Northfield (MN/USA), v. V, n. 3, p. 365-379, 1982.

KOCKA, Jürgen. Nur keinen neuen Sonderweg. Jedes Stück Entwestlichung wäre als Preis für die deutsche Vereinigung zu hoch. In: KOCKA, Jürgen. Interventionen: der Historiker in der öffentlichen Verantwortung. Göttingen: Vandenhoeck und Ruprecht, 2001. p. 68-77.

LAMOUNIER, Bolívar. Formação de um pensamento político autoritário na Primeira República. Uma interpretação. In: FAUSTO, Boris (dir.). História Geral da Civilização Brasileira. São Paulo: DIFEL, 1977. v. 9. p. 343-374.

LOVE, Joseph L. O regionalismo gaúcho. São Paulo: Perspectiva, 1975.

OLIVEIRA, Lúcia Lippi. Iberismo e americanismo. In: OLIVEIRA, Lúcia Lippi. Americanos: representações da identidade nacional no Brasil e nos EUA. Belo Horizonte: Editora UFMG, 2000. p. 47-67.

PETER, Jürgen. Der Historikerstreit und die Suche nach einer nationalen Identität der achtziger Jahre. Frankfurt/M: Peter Lang, 1995. Disponível em: <http://www.all-at-one. de/JuergenPeter/Historikerstreit2.pdf $>$.

PICCOLO, Helga Iracema Landgraf. Os Donos do Poder, de Raymundo Faoro. Cadernos IHU Ideias, São Leopoldo: UNISINOS, ano 2, n. 19, 2004.

POHLMANN, Friedrich. Der "Historikerstreit" in Deutschland, Eine rückblickende Bewertung. Transmitido pelo Südwestfunk (rádio), em 23 de janeiro de 2007; disponível em: < http://www.swr.de/swr2/programm/sendungen/essay/-/id=1866118/ property $=$ download/nid=659852/1 gmobfz/swr2-radioart-essay-20070123.rtf $>$.

RAMOS, Guerreiro. A crise do poder no Brasil. Rio de Janeiro: Zahar Editora, 1961.

SCHULZE, Winfried. Vom "Sonderweg" bis zur "Ankunft im Westen": Deutschlands Stellung in Europa. Geschichte in Wissenschaft und Unterricht, Berlim, n. 53, p. 226240, 2002. Disponível em: <http://www.historicum.net/fileadmin/sxw/Lehren_Lernen/ Schulze/Vom_Sonderweg_bis_zur_Ankunft_im_Westen.pdf $>$. 
SCHWARTZMAN, Simon. São Paulo e o Estado Nacional. São Paulo: DIFEL, 1975. SCHWARTZMAN, Simon. Bases do autoritarismo brasileiro. Rio de Janeiro: Campus, 1982.

SELL, Carlos Eduardo. Leituras de Weber e o Brasil: da política à religião, do atraso à modernidade. Ciências Sociais Unisinos, São Leopoldo, v. 43, n. 3, p. 241-248, 2007.

SOUZA, Jessé. A modernização seletiva: uma interpretação do sistema brasileiro. Brasília: Editora da Universidade de Brasília, 2000.

TARGA, Luiz Roberto Pecoits. 1893: interpretações da guerra. Ensaios FEE, Porto Alegre, v. 24, n. 1, p. 127-150, 2003a.

TARGA, Luiz Roberto Pecoits. Negações da identidade do Rio Grande do Sul. Ensaios FEE, Porto Alegre, v. 24, n. 2, p. 299-322, 2003 b.

TARGA, Luiz Roberto Pecoits. Le Rio Grande do Sul et la création de l'Etat "developmentiste" brésilien. Tese (Doutorado) - Université Pierre Mendes, Grenoble, 2002.

WEHLER, Hans-Ulrich. Raus aus der Sackgasse des "deutschen Sonderwegs"? In: WEHLER. Die Gegenwart als Geschichte. München: Beck, 1995. p. 181-185.

WEHLER, Hans-Ulrich."Deutscher Sonderweg” oder allgemeine Probleme des westlichen Kapitlismus? In: Wehler, Hans-Ulrich. Politik in der Geschichte. München: Beck, 1998. p. 78-92. 